\title{
Mudança institucional e gestão metropolitana no Brasil: o municipalismo autárquico e as finanças municipais metropolitanas
}

\author{
Antônio Sérgio Araújo Fernandes \\ Universidade Federal do Rio Grande do Norte \\ Robert H. Wilson \\ University of Texas at Austin
}

\begin{abstract}
O problema que este trabalho busca compreender possui o seguinte paradoxo: o federalismo municipalista, oriundo da Constituição de 1988, que, a princípio, traria como efeito perverso a crise da gestão metropolitana, devido aos problemas que enfrentou, sobretudo, de natureza fiscal e financeira nos municípios, terminou por se mostrar um jogo de soma zero para o conjunto da federação e representou um fator de estímulo ao reaparecimento da agregação intermunicipal do país. Isso se demonstra pela observação da retomada da gestão metropolitana no Brasil, a partir do final dos anos 1990 e na primeira década do século XXI. O procedimento de análise adotado para demonstrar este problema será histórico-institucional, tendo por base de explicação os processos de mudanças incrementais observados na gestão metropolitana brasileira.
\end{abstract}

Palavras-chave: mudança institucional; gestão metropolitana; finanças públicas metropolitanas.

Cambio institucional y gestión metropolitana en Brasil: el municipalismo autónomo y las finanzas municipales metropolitanas

El problema que este trabajo trata de entender tiene la siguiente paradoja: el federalismo municipal, derivado de la Constitución de 1988, que, en principio, inducir el efecto perverso de la crisis de la administración metropolitana, debido a los problemas que enfrentan, sobre todo de impuestos y municipios en los mercados financieros, terminaron por ser un juego de suma cero para la federación en su conjunto, y fue un factor que alienta la reanudación de la agregación entre las comunidades del país. Esta observación demuestra la reanudación de la gestión metropolitana en Brasil, a partir de la década de 1990 y la primera década de este siglo. El procedimiento de análisis adoptado para demostrar este problema será histórico e institucional, y la explicación básica de los procesos de cambios graduales observados en la gestión metropolitana de Brasil.

Palabras clave: cambio institucional; gestión metropolitana; finanzas municipales metropolitanas.

Artigo recebido em 3 jun. 2012 e aceito em 15 fev. 2013.

Rev. Adm. Pública - Rio de Janeiro 47(3):777-800, maio/jun. 2013 
Institutional change and metropolitan management in Brazil: autonomous localism, metropolitan and local finances

The problem that this paper seeks to understand has the following paradox: federalism municipal, derived from the 1988 Constitution, which, in principle, bring the perverse effect of the crisis of the metropolitan administration, because the problems faced, particularly tax and municipalities in financial, ended up to be a zero sum game for the whole federation, and was a factor encouraging the resumption of intercommunal aggregation of the country. This observation demonstrates the resumption of metropolitan management in Brazil, from the late 1990s and first decade of this century. The analysis procedure adopted to demonstrate this problem will be historical-institutional, and basic explanation of the processes of incremental changes observed in the Brazilian metropolitan management.

KEYWORDs: institutional change; metropolitan management; metropolitan and local finances.

\section{Introdução}

As regiões metropolitanas no Brasil possuem uma gama ampla de responsabilidades e áreas de atuação dentro de suas diversas legislações estaduais existentes. Estas incluem transporte público, infraestrutura urbana, resíduos sólidos e limpeza urbana, planejamento urbanístico, habitação, entre outras áreas. Apesar de serem importantes elementos de gestão subnacional, parecem indiferentes na maior parte das vezes aos políticos e governadores. Isso se dá pela ausência de uma legislação que cubra constitucionalmente as regiões metropolitanas com atribuições e recursos específicos. Desde a Constituição de 1988 que a responsabilidade pelas regiões metropolitanas ficou a cargo dos estados, tanto no sentido de sua regulação, quanto no que se refere ao provimento de recursos. Este é um problema básico abordado pela literatura que discute a questão metropolitana no Brasil (Spink, Teixeira e Clemente, 2009; Souza, 2003; Ribeiro, 2004; Garson, 2009). E uma das questões geradas oriundas deste problema é que os municípios, quando da definição do desenho federativo brasileiro, ao tornarem-se entes autônomos da federação, com direito a recursos de transferência, terminaram por inibir o desenvolvimento da esfera metropolitana no Brasil (Faria, 2008; Fernandes, 2006; Fernandes, 2004; Souza, 2003; Gouvêa, 2005).

Este trabalho busca analisar um dos grandes argumentos comumente utilizados pela literatura quando se observa a gestão metropolitana no Brasil, qual seja, o desenho institucional municipalista do federalismo brasileiro que inibe o desenvolvimento das regiões metropolitanas (RMs). O problema que este trabalho busca compreender possui o seguinte paradoxo: o federalismo municipalista, oriundo da Constituição de 1988, que, a princípio, traria como efeito perverso a crise da gestão metropolitana, devido aos problemas que enfrentou, sobretudo, de natureza fiscal e financeira nos municípios, terminou por se mostrar um jogo de soma zero para o conjunto da federação e representou um fator de estímulo ao reaparecimento da agregação intermunicipal do país. Isso se demonstra pela observação da retomada da gestão metropolitana no Brasil, a partir do final dos anos 1990 e na primeira década do século XXI. 
O referencial analítico para demonstrar este problema será histórico-institucional, tendo por base os processos de mudanças incrementais observados na gestão metropolitana brasileira.

Para abordar a questão acima indicada o artigo está dividido em 5 seções, além desta introdução e das considerações finais. A seção 2 trata do conceito de path dependency utilizado como referência de análise para mudança institucional e traz o problema que será abordado no caso das regiões metropolitanas a partir deste referencial teórico-conceitual. A seção 3 traz o momento crítico da gestão metropolitana brasileira com a crise da gestão metropolitana nos anos 1980 e a Constituição de 1988, que consagrou o municipalismo na política urbana. Na seção 4 aborda-se o municipalismo autárquico, seus problemas e como os efeitos deste tornam-se um estímulo à volta da gestão metropolitana. A seção 5 trata da retomada da gestão metropolitana no Brasil analisando os arranjos metropolitanos, suas limitações e os novos problemas oriundos deste novo momento da gestão metropolitana. A seção 6 traz as considerações finais do trabalho à guisa de conclusão.

\section{Path dependency como referencial de mudança institucional e sua aplicação no caso da gestão metropolitana brasileira}

No campo das ciências sociais, a path dependency é utilizada como a observação de uma determinada escolha institucional de política pública, que após experimentar um momento crítico inicia uma rota política que tem os custos para revertê-la, cada vez mais, aumentados. Existirão outros pontos de escolha política, mas as barreiras de certos arranjos institucionais obstruirão uma reversão fácil da escolha inicial. Dito de outro modo, em momentos críticos no desenvolvimento de um país — seja na política econômica, seja na política social, seja no processo de democratização política, estabelecem-se trajetórias amplas que são difíceis de reverter, mas dentro das quais existirão novos pontos de escolha para mudança mais adiante (Kato, 1996). Dentro do conceito de path dependency, duas noções são chave para sua compreensão: retornos crescentes e momento crítico. ${ }^{1}$ Retornos crescentes significam que a probabilidade de dar um passo à frente no mesmo caminho ou rota estabelecida aumenta cada vez que se avança no próprio caminho. Isso ocorre porque os benefícios relativos da atividade corrente, comparada com outras opções possíveis, aumentam com o tempo. Crescem os custos de sair da trilha de alguma alternativa previamente plausível. Assim, processos de retornos crescentes também podem ser descritos como autorreforço ou feedback positivo.

Este conceito geral de path dependency experimenta uma revisão no contexto atual que gira em torno da discussão de sua aplicação na observação dos fenômenos político-institucionais como elemento de explicação não apenas da estabilidade institucional, mas também de mudança institucional (Pierson, 2004, 2003; Thelen, 2003; Magnusson e Ottosson, 2009; Greener, 2005; Rezende, 2012). Fundamentalmente, as noções básicas de momento crítico

\footnotetext{
${ }^{1}$ Sobre momento crítico, ver D. Collier e R. Collier (1991).
} 
e retornos crescentes estão sendo discutidas, considerando suas lacunas como métodos de abordagem histórico-sociais.

Alguns questionamentos sobre esta perspectiva analítica são lançados mais recentemente por alguns estudiosos como Thelen (2003), Pierson (2003, 2004), Magnusson e Ottosson (2009), procurando dar conta de explicar até que ponto ocorre reprodução institucional e onde ao longo da trajetória ocorrerá mudança institucional. De acordo com Thelen (2003:209), a explicação por meio da path dependency é viável apenas ex post, pois ao longo da path há uma contínua mudança operada pelos atores políticos. Thelen argumenta com exemplos que os choques exógenos que induzem à inovação institucional no momento crítico deixam um legado que persiste por um largo período de tempo, mas ao longo da trajetória vão ocorrendo mudanças súbitas. Ou seja, os momentos críticos, por buscarem evidenciar grandes "quebras institucionais" que levam a inovações, podem obscurecer interessantes mecanismos de mudanças "subterrâneas" que são importantes ao longo da trajetória. Daí a dificuldade na opção da perspectiva analítica da path dependency em distinguir entre inovação e mudança institucional. Disso decorre que muitos elementos de mudança incremental que podem ser observados mais minuciosamente na realidade política experimentada ao longo da trajetória são subestimados. Como afirma Thelen (2003:219): "Momentos Críticos são atrativas explicações, mas por causa disto também decepcionantes quando querem entender a realidade política". Este é um ponto importante, pois não se tem a clareza quando, na abordagem de um fenômeno político institucional, da importância das pequenas mudanças capazes de gerar estabilidade. Isso só se torna possível quando se inserem na análise os atores; estes com sua dinâmica mostrarão as mudanças que ocorrem no curso da trajetória e no longo prazo, capazes de levar à inovação institucional estável. Em outras palavras, a política é uma contínua luta entre interesses e por isso é difícil distinguir entre estabilidade e mudança. Mudança como consequência de constante renegociação é um pré-requisito para a estabilidade (Thelen, 2003; Magnusson e Ottosson, 2009). É necessário, portanto, observar nas grandes narrativas históricas comparadas as estratégias dos atores que provocam mudanças incrementais na trajetória e evoluem chegando ao resultado de inovação institucional observada no momento crítico.

O trabalho de Magnusson e Ottosson (2009) procura analisar a relação entre persistência e mudança tendo como exemplo a trajetória do welfare state na Suécia. Para estes autores, uma boa parte dos historiadores que procuram explicar a evolução do welfare state sueco buscam elementos na trajetória deste que evidencie alguns de seus aspectos fortes que lograram estabilidade e que servem de exemplo como modelo de welfare state. Neste sentido, o "modelo sueco" é na maior parte das vezes autopropalado como um organismo que se desenvolveu ele mesmo sem que ninguém precisasse cuidá-lo. Este tipo de perspectiva histórico-analítica reforça apenas a dimensão retórica de análise do welfare state na Suécia (Cox, 2004:215). De fato, muitas mudanças políticas ocorreram ao longo do tempo, como diminuição de recursos e mudança de padrões institucionais, que tornam aquele momento crítico de origem do welfare state sueco, entre as décadas de 1920 e 1930 do século passado, já insuficiente para dar conta de explicar todas as mudanças pelas quais passou o sistema de bem-estar na Suécia. 
A path dependency é uma perspectiva interessante se há intenção de desenvolver uma metáfora sobre um determinado processo histórico institucional, como é o caso da estabilidade do welfare state sueco ou do desenvolvimento institucional italiano. Nesta perspectiva, busca-se um ponto de explicação histórica que dê conta de analisar a estabilidade do fenômeno. Isso pode ser bastante útil para a observação de um público maior interessado em história institucional, porém, para a comunidade de cientistas sociais, as lacunas geradas pela carência de microanálises, que procuram observar a dinâmica dos atores, geradora de mudanças incrementais, não proporcionam a visão efetivamente real da evolução institucional.

Em seu trabalho, Pierson (2004) mostra que a perspectiva analítica de sequência temporal com argumentos de feedback positivo ou autorreforço mais explica um foco de determinado fenômeno de investigação do que possui precisão e amplitude analítica. Neste sentido, segue pesadamente a tradição dos estudos de escolha racional, uma vez que se torna muito mais uma estrutura dedutiva de análise do que o acompanhamento empírico mais minucioso dos fatos. Este tipo de perspectiva de análise pode-se tornar "viciada" e, por conta disso, trazer sempre uma visão congelada do cenário político que se quer estudar. Para Pierson (2004:78) argumentos sobre sequências de trajetórias dependentes com foco em processos históricos amplos e demorados como industrialização, democratização e state building debruçam atenção sobre macroprocessos históricos com grandes cadeias causais que cobrem um espaço temporal de longo prazo. Entretanto, a path dependency como ferramenta analítica pode ser utilizada para analisar fenômenos de curto prazo por meio de microanálises, típicas das ciências sociais contemporâneas.

Para explicar a dinâmica de análise da política no horizonte temporal, Pierson constrói um quadro explicativo, buscando relacionar o horizonte de tempo da causa do fenômeno com o horizonte de tempo do resultado do fenômeno.

\section{Quadro 1}

\section{Horizontes de tempo em diferentes tipos de ciências sociais}

\begin{tabular}{|c|c|c|c|}
\hline & \multicolumn{2}{|c|}{ Tempo de Horizonte do Resultado } \\
\hline & & Curto Prazo & Longo Prazo \\
\hline \multirow{2}{*}{ 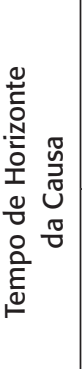 } & 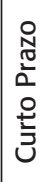 & I & $\begin{array}{l}\text { II } \\
\text { Efeitos Cumulativos }\end{array}$ \\
\hline & $\begin{array}{l}0 \\
\text { D̃ } \\
0 \\
0 \\
0 \\
0 \\
0 \\
0\end{array}$ & $\begin{array}{l}\text { III } \\
\text { Correntes } \\
\text { Causais } \\
\text { Limiares }\end{array}$ & $\begin{array}{l}\text { IV } \\
\text { Causas Cumulativas }\end{array}$ \\
\hline
\end{tabular}

Fonte: Extraído de Pierson (2004:92). 
O quadrante 1 refere-se a ambos, causas e resultados em curto prazo de tempo; trata-se de análises mais comumente observadas nas ciências sociais orientadas por variável ou estudos de caso acerca de problemas mais contingenciais. O quadrante 2 representa argumentos causais de curto prazo sobre efeitos cumulativos, que por definição referem-se a variáveis dependentes com longo tempo de horizonte. O quadrante 3 mostra que correntes causais com argumentos limiares invocam variáveis independentes com horizontes causais de longo prazo. O quadrante IV mostra que argumentos sobre causas cumulativas, ao contrário de argumentos de causas limiares, envolvem transformações lineares nas quais um pouco mais (com lenta movimentação) de "X" - causa (produz) um pouco mais (com lenta movimentação) de "Y" - resultados. Ou seja, argumentos de causas cumulativas implicam um horizonte de tempo de longo prazo para ambos, causas e resultados.

O caso das regiões metropolitanas aqui parece adequar-se mais ao quadrante 2 do esquema analítico de Pierson, pois as causas que levam à problemática das regiões metropolitanas são de curto prazo e o horizonte de tempo na observação de algum resultado mostra-se de longo prazo. Ou seja, com a Constituição de 1988 e a emergência do municipalismo, pensouse que ocorreria rapidamente o colapso das regiões metropolitanas, mas o que se observou na prática foi o contrário, o colapso no curto prazo do municipalismo autárquico é que levou à retomada da gestão metropolitana no Brasil. Daí que a cada movimento incremental de mudança institucional, a problemática da gestão metropolitana vai tomando novos contornos. Evidentemente que não é possível a aplicação de uma escolha conceitual definitiva neste caso, pois a opção metodológica do estudo é uma análise histórica e não orientada variável dependente. Entretanto, como se está hipotetizando aqui, a gestão metropolitana no Brasil se encontra ainda incompleta em termos de resultados. Isso decorreu de causas de curto prazo com efeitos cumulativos que estão se dando no longo prazo, a partir das pequenas mudanças incrementais que vêm sendo processadas. Acerca deste aspecto do que deve ser considerado de curto ou longo prazo na análise de um fenômeno histórico, uma pergunta que Pierson (2004:96) propõe é: quão longa deve ser a estrutura de tempo empregada no fenômeno social? Esta resposta "depende sobre que problema particular espera o investigador enfrentar, suas hipóteses sobre a natureza dos mais importantes processos que podem funcionar na área que ele está estudando, e julgamentos sobre a viabilidade de caminhos particulares de procedimento" (Pierson, 2004:96). Ou seja, se o problema dirige a pesquisa, obviamente o horizonte de tempo será arbitrado pelo pesquisador, dependendo do que ele pretende estudar e com que hipóteses está trabalhando. Sabe-se que macroprocessos históricos são analisados no longo prazo com causas e efeitos cumulativos, como são os exemplos dos trabalhos sobre a evolução da democracia: ver o caso do livro de Putnam (1996) sobre a Itália.

Assim, dentro deste referencial de análise, a pergunta que este trabalho procurará responder é: sob que condições a inovação constitucional de 1988 com o municipalismo, ao entregar unicamente aos estados a responsabilidade institucional da gestão metropolitana, dificultou ou criou barreiras a esta última? Esta questão será discutida a partir de uma perspectiva de interpretação da mudança institucional. Neste sentido, a abordagem aqui é gradualista, microanalítica, tendo por base de explicação os processos de mudanças incrementais 
observados após o marco constitucional de 1988, que são capazes de mostrar resultados ou algum resultado ao longo do tempo.

Para a construção do argumento analítico deste trabalho torna-se importante a discussão do trabalho de Souza (2003) sobre gestão metropolitana no Brasil sob o ponto de vista da path dependency. Basicamente, o argumento de Souza (2003:140) é que as escolhas feitas pelos constituintes de 1988, no momento crítico (critical juncture) da redemocratização, com a elaboração da Carta Magna, "influenciaram e foram influenciadas pelas escolhas feitas anteriormente em relação às entidades metropolitanas e a forma de administrar as grandes cidades". Apesar de Souza (2003) apontar no início do trabalho que existem retornos crescentes (increasing returns) no processo de evolução da gestão metropolitana pós-Constituição de 1988, o que se observa efetivamente é que sua preocupação ao longo do texto é explicar as relações intergovernamentais (RIGs)[sic] que influenciam a gestão metropolitana, antes que demonstrar o looping causal que levou a um novo "desenho" político-institucional para as RMs. Ou seja, o trabalho de Souza (2003) inicia uma perspectiva de análise acerca da path dependency sobre a gestão metropolitana, mas a deixa incompleta. Além disso, como se tratava ainda de um fenômeno sem amadurecimento em termos de indícios de efeitos de longo prazo, a análise de Souza (2003) trazida a valor presente tornou-se menos uma perspectiva histórica e mais um vaticínio futuro, o que é contrário à orientação histórica de análise com path depedency, que visa contabilizar o passado da dinâmica institucional e não especular cenários futuros.

O caso das regiões metropolitanas durante o processo decisório da Constituição de 1988 aponta para um choque ou quebra do padrão estabelecido até então, com a crise econômica e toda a falência do sistema de política urbana do regime militar, fortemente centralizado no governo federal. A conjuntura da época apontou para um novo arranjo institucional acerca das regiões metropolitanas que seria diferente do que estava estabelecido durante o regime militar, em que o municipalismo das políticas públicas dominava a questão federativa na agenda Constitucional. Entretanto, o "municipalismo autárquico", oriundo da Constituição de 1988, que, a princípio, traria como efeito perverso a crise da gestão metropolitana, devido aos problemas que enfrentou, sobretudo, de natureza fiscal e financeira nos municípios, terminou se mostrando, no médio e longo prazos, como um jogo de soma zero para o conjunto da federação, sendo um fator de estímulo ao reaparecimento da agregação intermunicipal do país. Isso se demonstra pela observação da retomada da gestão metropolitana no Brasil a partir do final dos anos 1990 e da primeira década do século XXI.

Assim, a princípio, apesar de logo após a Constituição de 1988, sobretudo nos anos 1990, o novo marco constitucional ter sido um estímulo negativo à gestão metropolitana, uma vez que se nota um vazio político e administrativo com relação à esfera metropolitana, verifica-se, a partir da primeira década do século XXI, a retomada da questão metropolitana com a criação de mais de 40 regiões metropolitanas, áreas metropolitanas, aglomerações urbanas e regiões de desenvolvimento. 
Assim, no caso da gestão das RMs, com o federalismo municipalista da Constituição de 1988, houve uma mudança, com um horizonte de causa de curto prazo, mas que possui um tempo de horizonte de resultado de longo prazo. Disso decorre que a gestão metropolitana no Brasil é hoje um fenômeno muito mais aberto a mudanças institucionais do que autorreforçando uma trajetória. Os fatos que corroboram isso são a criação de mais de 40 áreas ou regiões metropolitanas no país.

\section{A gestão metropolitana brasileira em seu momento crítico}

As regiões metropolitanas foram instituídas originalmente pelo governo federal por Lei Complementar no 14 de $1973^{2}$ e teriam a responsabilidade constitucional nas seguintes atribuições: planejamento integrado do desenvolvimento econômico e social; saneamento básico (água, esgoto e limpeza urbana); aproveitamento dos recursos hídricos e controle da poluição ambiental; produção e distribuição de gás combustível canalizado; transportes e sistema viário e uso e ocupação do solo (Garson, 2009; Souza, 2003; Faria, 2008). Na prática, o que se observou acerca da ação da esfera metropolitana sobre todas essas atribuições é que as companhias metropolitanas de planejamento terminaram por realizar somente o planejamento de cunho urbanístico. A estrutura de gestão das RMs era composta por um Conselho Deliberativo e um Conselho Consultivo, mantido com recursos estaduais. O Conselho Deliberativo seria nomeado pelo governador estadual. Um membro representaria o município da capital e o outro, os demais municípios. O Conselho Consultivo, composto por representantes dos municípios, seria presidido pelo presidente do Conselho Deliberativo, garantindo que o poder decisório se mantivesse com o governo estadual (Garson, 2009).

A crise econômica do final dos anos 1970 e início dos anos 1980 traz uma escassez de recursos para o governo federal, com isso decorrendo a crise do planejamento governamental brasileiro, que no sistema de política urbana é duramente afetado com a extinção do Banco Nacional de Habitação (BNH), principal fonte de recursos da política urbana. Toda a estrutura de política de desenvolvimento urbano, baseada no planejamento integrado, que em grande parte dependia de recursos do $\mathrm{BNH}$, entra em crise e isso não seria diferente com a gestão das regiões metropolitanas.

A promulgação da Carta Constitucional em 1988 consagrou a autonomia municipal, passando os municípios, a partir de então, a compor o pacto federativo com União, estados e Distrito Federal. Além das competências concorrentes e partilhadas com estados e União, e da definição e partilha das receitas tributárias, a capacidade de elaboração de leis orgânicas

\footnotetext{
${ }^{2}$ Pela Lei Complementar Federal no 14, de 8 de junho de 1973, art. 2º, são criadas oito regiões metropolitanas. São elas: Belém, Fortaleza, Recife, Salvador, Belo Horizonte, São Paulo, Curitiba, Porto Alegre. A nona região metropolitana do país, a do Rio de Janeiro, seria criada no ano subsequente, em 1974, pela Lei Complementar no 20 , de 1o de julho de 1974, após a fusão dos estados do Rio de Janeiro e da Guanabara.
} 
é uma conquista importante. No que se refere à política urbana (arts. 182 e 183), ${ }^{3}$ a Carta Magna consagra a participação popular no processo de gestão. Entre outras coisas, ficou estabelecido que as leis orgânicas devessem ter como preceito a cooperação das associações representativas no planejamento municipal (inciso X do art. 29). Além disso, estabeleceu-se também na Constituição de 1988, acerca da participação popular diretamente ligada à política municipal: consulta por meio de plebiscito à população interessada quando da fusão, incorporação ou desmembramento de municípios (§ 4 do art. 18); iniciativa popular em projetos de lei de interesse específico do município, da cidade ou de bairros, mediante manifestação de pelo menos 5\% do eleitorado (inciso XI do art. 29); colocação das contas dos municípios à disposição de qualquer contribuinte durante 60 dias para exame, apreciação, podendo ser questionadas (§ 3 o do art. 51).

O saldo com este contexto marcou a Constituinte, com a coalizão pró-municipalismo ficando vitoriosa. Com o marco constitucional de 1988 concedendo unicamente aos estados toda a competência da gestão metropolitana, pensou-se que isso fosse reprimir a criação das regiões metropolitanas, porém o que aconteceu foi o contrário; a partir dos anos 1990, observa-se a criação de RMs no país. Acerca do argumento, da diversidade de arranjos institucionais, isso é um fato observado nas diversas experiências de criação e gestão metropolitana (Spink, Teixeira e Clemente, 2009:6). Acredita-se que este se constitui no trade off do processo de evolução da gestão metropolitana.

Ainda assim, as regiões metropolitanas não se tornaram uma esfera de gestão do território "esquecida", que entrou em decadência, culminando com sua extinção. Ou seja, do ponto de vista da abordagem histórico-institucional, não se observa após a Constituição de 1988 um cenário de reforço que caracterizasse uma trajetória claramente definida capaz de levar à sua extinção. Além disso, no que se refere ao marco constitucional, também não se nota uma total falta de tratamento legislativo federal desta matéria. Tramita ainda em discussão no Congresso Nacional, desde 2004, uma proposta de regulamentação para as regiões metropolitanas - Estatuto das Metrópoles — Projeto de Lei no 3.640/2004. Isso também mostra que o momento não é de estabelecimento de trajetórias institucionais na gestão metropolitana, porém ele ainda está aberto aos eventos institucionais que se seguirão nos próximos anos.

\section{O municipalismo autárquico pós-Constituição de 1988 e as regiões metropolitanas}

Um dos maiores problemas enfrentados na federação brasileira é a autonomia municipal visà-vis a baixa capacidade fiscal, financeira e institucional dos municípios para absorver e dar conta de todas as suas funções constitucionais, incluindo-se aí a política urbana (Abrucio,

\footnotetext{
${ }^{3}$ Os arts. 182 e 183 da Constituição foram regulamentados pelo Estatuto da Cidade — Lei no 10.257 , de 10 de julho de 2001 .
} 
2005; Afonso, 2000; Melo, 1996; Almeida, 2005; Arretche, 2000; Souza, 1999). A baixa capacidade financeira dos municípios brasileiros ocorre mesmo com a partilha de tributos federais e estaduais que são repassados para estes, além de transferências constitucionais vinculadas para execução das políticas sociais, sobretudo, nas áreas de saúde e educação.

Em 2010, segundo o Censo IBGE, o Brasil possuía 5.565 municípios com uma população de 190.732.694 milhões de habitantes. A maioria da população brasileira — 123 milhões de pessoas - vive em municípios pequenos, mais precisamente, em 5.452 municípios que têm população abaixo de 200 mil habitantes. Apenas 35,25\% (67,2 milhões) dos brasileiros vivem nos 133 municípios (2,39\% do total de municípios) com população acima de 200 mil habitantes. A maioria dos municípios brasileiros acumula uma série de problemas, especialmente no que se refere à execução de suas atribuições constitucionais de políticas sociais e também de política urbana. Um dos problemas que leva a esta realidade é que a maioria dos municípios brasileiros tem baixa capacidade tributária e depende quase que exclusivamente de transferências intergovernamentais como fonte de recursos.

As transferências intergovernamentais permitiram que os municípios tivessem um incremento substancial de receitas disponíveis, algo que foi evoluindo bastante ao longo das décadas, como mostra a tabela 1. Em 1960, os municípios tinham um acréscimo de apenas $2 \%$ entre sua arrecadação própria e o que ficava como receita disponível como receita. Já em 2007 observa-se que têm um acréscimo de 14\% entre o que arrecadam e o que têm disponível.

Tabela 1

Arrecadação própria e receitas disponíveis: União, estados e municípios (1960-2007)

\begin{tabular}{|lllccccccc|}
\hline \multirow{2}{*}{ Ano } & \multicolumn{4}{c}{ Arrecadação própria } & \multicolumn{5}{c|}{ Receitas disponíveis } \\
\cline { 2 - 9 } & União & Estados & Municípios & Total & União & Estados & Municípios & Total \\
\hline 1960 & 63,90 & 31,30 & 4,70 & 100 & 59,40 & 34,10 & 6,50 & 100 \\
1980 & 72,80 & 24,00 & 3,20 & 100 & 66,20 & 24,30 & 9,50 & 100 \\
1992 & 62,2 & 32,3 & 5,5 & 100 & 52,10 & 31,00 & 16,90 & 100 \\
2000 & 67,60 & 27,42 & 4,98 & 100 & 53,20 & 27,70 & 19,10 & 100 \\
2007 & 69,1 & 25,7 & 5,2 & 100 & 53,49 & 26,93 & 19,58 & 100 \\
\hline
\end{tabular}

Fontes: Rezende (1995), para os anos de 1960-92; Caldas (2002), para o ano de 2000; Confederação Nacional dos Municípios (2009), para o ano de 2007.

Com a redistribuição do bolo tributário federativo oriundo da Constituição de 1988, os pequenos municípios experimentaram uma situação em que poderiam gozar de autonomia política mesmo com dependência financeira de transferências e quase nenhuma força de arrecadação tributária. Evidentemente que no final este estímulo inicial se mostrará no longo prazo um jogo de soma zero, pois os municípios não terão condições, apenas com transferências e baixa capacidade tributária, de manter suas funções constitucionais, incluindo aí a política urbana.

No Brasil, existe uma forte concentração da receita tributária nos municípios de maior porte populacional e demográfico, que são aqueles mais urbanos. Em 2009 pode-se observar 
que estes municípios, com população superior a 200 mil habitantes, concentram 72,65\% de toda a receita tributária do conjunto dos municípios do país. Em oposição, verifica-se que 70,47\% dos municípios, que possuem população abaixo de 20 mil habitantes, detêm apenas $4,7 \%$ do total da receita tributária do conjunto dos municípios brasileiros, conforme mostra a tabela 2. Vale a pena registrar que os dois maiores e mais populosos (São Paulo e Rio de Janeiro) concentram $32,2 \%$ de toda a receita tributária arrecadada pelo conjunto dos municípios do país (Bremaeker, 2010).

\section{Tabela 2}

Distribuição da receita orçamentária municipal e da receita tributária municipal, segundo os grupos de habitantes Brasil - 2009 (em R\$ 1,00)

\begin{tabular}{|cccc|}
\hline $\begin{array}{c}\text { Grupos de } \\
\text { Habitantes } \\
\text { (por mil) }\end{array}$ & $\begin{array}{c}\text { Receita } \\
\text { Orçamentária } \\
\text { Municipal }\end{array}$ & $\begin{array}{c}\text { Receita } \\
\text { Tributária } \\
\text { Municipal }\end{array}$ & $\begin{array}{c}\text { \% da Receita Tributá- } \\
\text { ria Municipal }\end{array}$ \\
\hline BRASIL & 273.028 .483 .116 & 47.019 .621 .431 & 100,0 \\
Até 2 & 632.264 .574 & 13.316 .891 & 0,03 \\
2 I-- 5 & 8.819 .204 .729 & 282.655 .559 & 0,60 \\
5 I-- 10 & 13.472 .232 .435 & 618.649 .301 & 1,32 \\
$101--20$ & 25.277 .245 .136 & 1.295 .395 .105 & 2,76 \\
$201--50$ & 39.861 .685 .022 & 3.307 .260 .873 & 7,03 \\
$501--100$ & 27.734 .037 .242 & 3.113 .389 .655 & 6,62 \\
$1001--200$ & 27.854 .975 .010 & 4.229 .491 .032 & 9,00 \\
$2001--500$ & 39.281 .722 .289 & 7.258 .763 .895 & 15,44 \\
500 I-- 1000 & 24.033 .487 .871 & 4.716 .601 .451 & 10,03 \\
1000 1-- 5000 & 29.530 .861 .532 & 7.429 .582 .483 & 15,80 \\
5000 e mais & 36.530 .767 .276 & 14.754 .515 .186 & 31,38 \\
\hline
\end{tabular}

Fonte: Bremaeker (2010), a partir de dados da Secretaria do Tesouro Nacional (STN).

Ao observar esta questão de modo comparado internacionalmente, qual seja, o peso relativo da arrecadação tributária e das transferências na receita disponível dos municípios, verifica-se que o Brasil é um caso muito particular neste sentido. A tabela 3 mostra comparativamente a composição da receita dos municípios brasileiros com a de outros países que são federações, ou seja, organizados em três níveis de governo. Constata-se que o peso da arrecadação tributária municipal brasileira em termos relativos é pífio, quando comparado com os demais governos locais desta série de países da tabela, mesmo os países em desenvolvimento da América Latina (México e Colômbia) e também a África do Sul. 
Tabela 3

Composição da receita de governos estaduais e locais em alguns países organizados em três níveis de governo (em\%)

\begin{tabular}{|lcccc|}
\hline Países & Arrecadação Tributária & Recursos de Transferências & Outras Receitas & Total \\
\hline Brasil (1998) & 20 & 65 & 15 & 100 \\
México (2000) & 58 & 27 & 14 & 100 \\
Canadá (2002) & 43 & 39 & 19 & 100 \\
EUA (2001) & 38 & 40 & 22 & 100 \\
Austrália (2001) & 38 & 17 & 45 & 100 \\
Alemanha (2002) & 37 & 35 & 28 & 100 \\
Colômbia (2000) & 28 & 31 & 41 & 100 \\
Espanha (2000) & 51 & 36 & 13 & 100 \\
África do Sul (2002) & 23 & 18 & 59 & 100 \\
Média Exceto Brasil & 40 & 30 & 30 & 100 \\
\hline
\end{tabular}

Fonte: Mendes et al. (2008), a partir de dados do FMI (Government statistics yearbook, 2003).

Todo este contexto leva a um problema no federalismo municipalista brasileiro, especialmente nos pequenos municípios do país. Estes têm baixa capacidade tributária, dependem bastante de transferências e suas despesas são rígidas, dado que possuem recursos que são vinculados, o que não os torna capazes de realizar investimentos e desenvolver política urbana autonomamente.

Nas regiões metropolitanas o quadro geral com relação ao peso das receitas tributárias no conjunto das receitas orçamentárias mostra-se diferente da maioria dos municípios do Brasil, conforme mostra a tabela 4. Entretanto, observa-se que o peso da receita tributária em relação à receita orçamentária vem diminuindo nos municípios metropolitanos. As capitais mostram em média, no período entre 2003 e 2006, que a arrecadação tributária compõe apenas 36\% de suas receitas orçamentárias, e quando se observam as cidades médias das regiões metropolitanas no mesmo período, este valor médio cai para $21 \%$. É uma situação melhor que a maioria dos municípios brasileiros, evidentemente; ainda assim, o problema da dependência das receitas de transferências em municípios metropolitanos requer alerta, mas não se constitui em algo tão crônico como na maioria dos municípios brasileiros.

Tabela 4

Relação receitas tributárias/receitas orçamentárias (em \%)

\begin{tabular}{|llll|}
\hline & \multicolumn{3}{c|}{ Receitas Tributárias/Receitas Orçamentárias } \\
\cline { 2 - 4 } & $1995-98$ & $1999-2002$ & $2003-06$ \\
\hline Capital Estadual & 42,57 & 35,63 & 36,06 \\
Cidades Médias Metropolitanas & 28,67 & 22,46 & 21,05 \\
Cidades Médias não Metropolitanas & 22,22 & 15,19 & 17,14 \\
Demais Municípios & 13,02 & 12,70 & 9,70 \\
\hline
\end{tabular}

Fonte: Penalva Santos (2008), a partir de dados da Secretaria do Tesouro Nacional (STN). 
Caso se observe o comportamento na média geral das receitas tributárias exclusivamente em municípios metropolitanos, pode-se verificar que existe aí uma diferença entre o município núcleo ou sede e os demais municípios metropolitanos, conforme mostra a tabela 5. Nos municípios núcleos a receita tributária compõe em média $32 \%$ das receitas correntes, enquanto para os demais municípios metropolitanos este valor diminui, passando as receitas tributárias a compor apenas $20 \%$ das receitas orçamentárias. Ou seja, em termos de autonomia tributária — relação entre receita tributária e receita orçamentária (receita total) —, os grandes números evidenciam a superioridade dos municípios núcleos em relação aos demais municípios metropolitanos. Mesmo entre os municípios núcleos serão encontradas desigualdades. Capitais fortemente concentradoras de renda e população, como Rio de Janeiro e São Paulo, vão ter níveis de autonomia tributária muito acima da média geral, enquanto municípios núcleos que se constituem em cidades médias vão apresentar níveis de autonomia tributária abaixo da média observada.

Tabela 5

Composição da receita tributária no total da receita orçamentária em municípios metropolitanos e não metropolitanos em 2010*

\begin{tabular}{|lllll|}
\hline & \multicolumn{2}{c}{ Receita Total } & \multicolumn{3}{c|}{ Receitas Tributárias } \\
\cline { 2 - 5 } & $\mathrm{R} \$$ & $\%$ & $\mathrm{R} \$$ & $\%$ \\
\hline Munić́pios Metropolitanos & $163.079 .850 .888,74$ & 100 & $43.718 .701 .989,15$ & 27 \\
Munićípios não Metropolitanos & $69.123 .466 .317,42$ & 100 & $12.487 .442 .437,80$ & 20 \\
Munić́pios Núcleos Metropolitanos & $99.720 .548 .291,99$ & 100 & $31.231 .259 .551,35$ & 31 \\
\hline
\end{tabular}

Fonte: Tabulação própria a partir de dados da Secretaria do Tesouro Nacional (STN). Disponível em: <www.tesouro.fazenda.gov.br/estados_municipios/sistn.asp>. Acesso entre: 1 nov. 2011 e 1 mar. 2012.

* A lista de regiões metropolitanas, com os respectivos municípios componentes, utilizada para o cálculo da tabela foi baseada na pesquisa do Observatório das Metrópoles, que foi publicada no trabalho organizado por Ribeiro (2009).

A baixa capacidade tributária da maioria dos municípios metropolitanos se reflete na despesa com a rigidez do orçamento total. Garson (2009:176-177), com base em dados financeiros de uma série que vai de 1998 a 2003, observa que a rigidez do orçamento total nos municípios metropolitanos ocorre devido ao gasto público se orientar para a aplicação de recursos vinculados à execução de políticas públicas e de transferências discricionárias, geralmente destinadas a áreas, setores e investimentos específicos. A tabela 6 mostra que, no ano de 2010, do total das despesas correntes de 2010, a despesa de pessoal representa nos municípios metropolitanos, excluindo-se o município núcleo, mais de $43 \%$ do total das despesas. O que corrobora a ideia demonstrada por Garson (2009) para os anos de 1998 a 2003 de que o elevado nível de vinculação de receitas, aliado a uma intensa prestação de serviços de mão de obra intensiva, resultam em forte rigidez do gasto público nos municípios metropolitanos tanto em capitais quanto nos demais municípios. Essa rigidez do gasto se manifesta na forte despesa com pessoal. 
Tabela 6

Despesas nos municípios metropolitanos no ano de $2010^{*}$

\begin{tabular}{|c|c|c|c|c|c|c|}
\hline \multirow[b]{2}{*}{ DESPESAS POR GRUPO } & \multicolumn{2}{|c|}{$\begin{array}{c}\text { Municípios } \\
\text { Metropolitanos }\end{array}$} & \multicolumn{2}{|c|}{$\begin{array}{l}\text { Mun. Metropolitanos } \\
\text { Exceto o Município } \\
\text { Núcleo }\end{array}$} & \multicolumn{2}{|c|}{$\begin{array}{l}\text { Município Núcleo } \\
\text { Metropolitano }\end{array}$} \\
\hline & $\begin{array}{l}\text { Em R\$ } \\
\text { bilhões }\end{array}$ & $\%$ & Em R\$ bilhões & $\%$ & Em $R \$$ bilhões & $\%$ \\
\hline Despesa Total & $R \$ 141,60$ & 100,0 & $R \$ 49,10$ & 100,0 & $\mathrm{R} \$ 92,50$ & 100,0 \\
\hline Despesa Corrente & $\mathrm{R} \$ 122,60$ & 86,6 & $\mathrm{R} \$ 42,10$ & 85,82 & $R \$ 80,50$ & 87,02 \\
\hline Pessoal & $R \$ 56,20$ & 39,7 & $R \$ 21,20$ & 43,34 & $R \$ 34,90$ & 37,73 \\
\hline Juros e Encargos de Dívida & $\mathrm{R} \$ 3,73$ & 2,7 & $R \$ 0,40$ & 0,64 & $R \$ 3,50$ & 3,78 \\
\hline Outras Despesas Correntes & $R \$ 62,65$ & 44,2 & $\mathrm{R} \$ 20,50$ & 41,84 & $\mathrm{R} \$ 42,10$ & 45,51 \\
\hline Despesas de Capital & $\mathrm{R} \$ 18,91$ & 13,4 & $\mathrm{R} \$ 7,00$ & 14,28 & $R \$ 12,00$ & 12,97 \\
\hline
\end{tabular}

Fonte: Tabulação própria a partir de dados da Secretaria do Tesouro Nacional (STN), Disponível em: <www.tesouro.fazenda.gov.br/estados_municipios/sistn.asp>. Acesso entre: 1 nov. 2011 e 1으. 2012.

* A lista de regiões metropolitanas, com os respectivos municípios componentes, utilizada para o cálculo da tabela foi baseada na pesquisa do Observatório das Metrópoles, publicada no trabalho organizado por Ribeiro (2009).

No que se refere aos gastos dos municípios metropolitanos com programas urbanos - saneamento, habitação, urbanismo, transporte - observa-se que essas despesas ocupam poucos recursos, como mostra a tabela 7: cerca de $30 \%$ do total de despesas por função, ainda que seja responsabilidade municipal a política urbana. Caso observemos os municípios metropolitanos, excluindo-se os municípios núcleos, isso cai para $27 \%$ do total das despesas por função municipal. Nos municípios metropolitanos que são núcleos, as despesas ligadas a funções urbanas ocupam 33\% do total das despesas por função. Mais uma vez observa-se a desigualdade na aplicação de recursos entre os municípios metropolitanos núcleos e demais municípios. As despesas por funções que ocupam a maior parte dos recursos dos municípios metropolitanos são saúde e educação, cerca de $70 \%$ do total de despesas por função. E os municípios metropolitanos, excluindo-se os municípios núcleos, gastam um pouco mais de recursos nessas duas áreas do que as capitais e municípios núcleos. Talvez isso se deva ao fato do maior volume de transferências que os municípios médios recebem em comparação às capitais e cidades grandes que são municípios núcleos. 
Tabela 7

Despesas municipais por função em municípios metropolitanos em 2010*

\begin{tabular}{|c|c|c|c|c|c|c|}
\hline DESPESAS POR FUNÇÃO & $\begin{array}{c}\text { Municípios } \\
\text { Metropolitanos } \\
\text { (em R\$ bilhões) }\end{array}$ & $\%$ & $\begin{array}{l}\text { Mun. } \\
\text { Metropolitanos } \\
\text { Exceto Mun. } \\
\text { Núcleo (em } \\
\text { R\$ bilhões) }\end{array}$ & $\%$ & $\begin{array}{c}\text { Munic. } \\
\text { Núcleo } \\
\text { Metropolitano } \\
\text { (em R\$ bilhões) }\end{array}$ & $\%$ \\
\hline Segurança Pública & 1,62 & 1,67 & 0,64 & 1,65 & 0,90 & 1,69 \\
\hline Saúde & 32,2 & 33,98 & 12,6 & 32,32 & 20,30 & 35,10 \\
\hline Trabalho & 0,50 & 0,51 & 0,22 & 0,57 & 0,30 & 0,48 \\
\hline Educação & 32,1 & 33,20 & 14,8 & 38,04 & 17,40 & 29,94 \\
\hline Urbanismo & 16,9 & 17,44 & 6,64 & 17,05 & 10,20 & 17,71 \\
\hline Habitação & 2,6 & 2,65 & 0,72 & 1,84 & 1,80 & 3,19 \\
\hline Saneamento & 4,8 & 4,92 & 1,93 & 4,96 & 2,80 & 4,89 \\
\hline Gestão Ambiental & 1,41 & 1,46 & 0,57 & 1,45 & 0,84 & 1,46 \\
\hline Transporte & 4,73 & 4,17 & 0,82 & 2,11 & 3,20 & 5,55 \\
\hline Total de Despesas por Função & 96,86 & 100,00 & 38,9 & 100,00 & & 100,00 \\
\hline
\end{tabular}

Fonte: Tabulação própria a partir de dados da Secretaria do Tesouro Nacional (STN). Disponível em: <www.tesouro.fazenda.gov.br/estados_municipios/sistn.asp>. Acesso entre: 1으ov. 2011 e 1ำ mar. 2012.

* A lista de regiões metropolitanas, com os respectivos municípios componentes, utilizada para o cálculo da tabela foi baseada na pesquisa do Observatório das Metrópoles, publicada no trabalho organizado por Ribeiro (2009).

Com a rigidez orçamentária observada, a capacidade de investimento municipal cai bastante, sobretudo para os municípios metropolitanos que não são núcleo ou capital estadual; daí a importância da formação de arranjos metropolitanos e, dentro deles, o estabelecimento de fundos metropolitanos e também de consórcios metropolitanos para a realização de investimentos em obras de infraestrutura e também para a prestação de serviços urbanos como transporte e limpeza urbana. Importante frisar que, dos 447 municípios que compunham as regiões metropolitanas e RIDES no país até 2009, 290 (64,8\%) eram municípios com menos de 100 mil habitantes, portanto, municípios pequenos que possuem todos os problemas de dependência de recursos de transferência e carência para financiar e prover serviços e infraestrutura urbana.

Os poucos recursos destinados à área urbana pelos municípios, aliados à pouca margem de recursos para investimento, são o estímulo para a agregação intermunicipal metropolitana. Ao longo do final da década de 1990 até aqui, foram criadas mais de 30 regiões metropolitanas (RMs) e algumas regiões de desenvolvimento (Rides).

\section{Os arranjos institucionais metropolitanos no Brasil}

Na gestão metropolitana observar-se-á o problema típico de ação coletiva, enunciado por Olson (1969:47): os governos municipais em áreas metropolitanas que constroem estradas 
vicinais ou realizam melhorias urbanas diversas com impacto para além de sua jurisdição, o fazem em condições subótimas. Isso se deve ao fato de que o ônus tenderá a ser arcado pelos municípios maiores, ou pela cidade núcleo. Ou seja, na formação de arranjos metropolitanos, a capital ou o município núcleo tem um papel central na organização propriamente dita da RM, e ao mesmo tempo é o município que mais "perderá", pois provavelmente dispensará mais recursos nos fundos e consórcios que a RM venha a constituir com os municípios médios e pequenos. Além do problema de assimetria de porte intrametropolitana, um problema recorrente quando se trata de gestão metropolitana no Brasil refere-se ao papel dos governos estaduais. O posicionamento de apoio dos governos estaduais às questões metropolitanas torna-se um elemento fundamental na gestão metropolitana. Entretanto, pode-se afirmar que se nota certo desinteresse por parte dos governos estaduais pela gestão metropolitana. De acordo com Gouvêa (2005), a maioria das constituições estaduais resume a importância da região metropolitana à existência de um artigo que reproduz na íntegra o dispositivo previsto no art. 25, § 3ํㅡㄹ da Constituição brasileira de 1988. Ainda Gouvêa (2005) assinala que muitos dos territórios metropolitanos criados após 1988 nem poderiam ser considerados metropolitanos, pois não possuem densidade demográfica e uma situação de conurbação entre os municípios limítrofes.

Entretanto, a maioria das leis complementares estaduais que regulam os princípios normativos das regiões metropolitanas no Brasil possui critérios diversos. Com isso observase a existência vários modelos diferenciados de institucionalização do arranjo institucional metropolitano. Além disso, observam-se também dificuldades em relação à participação e representatividade dos municípios-membros. Por todas estas razões, a compreensão do arranjo institucional se torna um elemento de análise relevante. Diante da ausência ainda de um dispositivo infraconstitucional regulando mais detalhadamente a matéria, a regulação metropolitana unicamente regida por critérios exclusivamente estaduais aponta para uma heterogeneidade de modelos, daí a importância dos estudos e análises de casos comparados em RMs pelo país.

A análise acerca dos arranjos metropolitanos se deterá a observar a existência dos cinco elementos que são fundamentais hoje na gestão metropolitana, quais sejam: Conselho Metropolitano, Agência Metropolitana, Fundo Metropolitano, Legislativo Metropolitano e Consórcio Metropolitano. Para a análise, aqui será utilizado como referência o quadro 2, oriundo do trabalho de Ribeiro e Santos Junior (2010), que traz o apontamento sobre a existência e o funcionamento dos elementos de gestão acima mencionados.

Ao observar o quadro 2, em 2009 só se dispunha de informação acerca do arranjo institucional de 25 RMs. Importante notar que apenas quatro RMs foram criadas de 2010 até aqui, e do ano de 2009 até 2012 foram criadas oito regiões metropolitanas. A maioria das regiões metropolitanas, mais de $60 \%$ destas, foi criada a partir do ano 2000 . Isso mostra que a maioria das regiões metropolitanas está em formação e se constituindo originariamente, mais do que se consolidando neste momento no país. E mesmo as mais antigas, que vêm desde 1973, têm ainda um longo caminho a percorrer em termos de gestão, como será visto no capítulo seguinte. 
Observando ainda o quadro 2, em quase todas as 23 RMs descritas no quadro observase a presença do Conselho Metropolitano. Parece que, com exceção da RM de Salvador, todas as demais RMs do quadro 2 mostram a presença de Conselho Metropolitano ou Conselho Similar, como Conselho de Desenvolvimento ou Conselho Gestor. Ou seja, o conselho metropolitano termina sendo o elemento colegiado máximo predominante do arranjo institucional metropolitano brasileiro. Torna-se importante observar a natureza institucional dos conselhos, suas regras existentes e se realmente estão em funcionamento, dado que este aspecto pode ser decisivo na observação da governabilidade da região metropolitana.

No que se refere à existência de Fundo Metropolitano, seis regiões metropolitanas apontam possuí-lo em seu arranjo institucional; são elas: Belém, Belo Horizonte, Recife, Maceió, Vale do Aço (MG), Grande Vitória. O fundo é um elemento importante na gestão metropolitana, pois compõe os recursos necessários a serem partilhados para o financiamento dos serviços públicos essenciais nos municípios. Também é importante, no caso dos fundos metropolitanos, como estão distribuídos os recursos, de modo a observar se o problema de assimetria de porte é minimizado quando no estabelecimento do fundo.

A agência metropolitana está presente apenas em quatro RMs - Vale do Aço (MG), Campinas, Baixada Santista e Belo Horizonte. Existem companhias metropolitanas de gestão em três RMs: Salvador (Conder), Recife (Fidem), São Paulo (Emplasa), companhias estas que são oriundas no regime militar e que ainda estão em funcionamento. Evidentemente que elas funcionam hoje sob outra dinâmica político-institucional, sem a mesma força política e de recursos que tinham quando eram tecnoburocracias estaduais, mas procurando inserir-se no novo arranjo metropolitano que foi se constituindo ao longo do tempo, como é o caso de São Paulo e Recife.

O parlamento metropolitano é observado em apenas duas regiões metropolitanas das 25 que compõem o quadro, nas RMs de Natal e Maringá. Evidentemente que a dinâmica de funcionamento destes dois parlamentos metropolitanos requer observação mais acurada, dadas as dificuldades de organizar municípios em torno de um mesmo fórum participativo.

Quadro 2

\begin{tabular}{|c|c|c|}
\hline RM & Ano de Criação & Tipo de Arranjo \\
\hline Belém & 1973 & $\begin{array}{l}\text { Conselho Metropolitano, que dispõe de uma Secretaria Geral, e Fundo de Desen- } \\
\text { volvimento da Região Metropolitana de Belém. }\end{array}$ \\
\hline Belo Horizonte & 1973 & $\begin{array}{l}\text { Assembleia Metropolitana, Conselho Deliberativo de Desenvolvimento Metropo- } \\
\text { litano, Agência de Desenvolvimento Metropolitano, Fundo de Desenvolvimento } \\
\text { Metropolitano, Secretaria de Estado de Desenvolvimento Regional e Política Urbana, } \\
\text { Grupo de Governança Metropolitana, Fórum Metropolitano da RMBH, Associação } \\
\text { dos Municípios da Região Metropolitana de Belo Horizonte e Fórum Mineiro de } \\
\text { Reforma Urbana. }\end{array}$ \\
\hline Curitiba & 1973 & $\begin{array}{l}\text { Coordenação da Região Metropolitana de Curitiba (Comec), Conselhos Consultivo } \\
\text { e Deliberativo, Secretaria Municipal (Curitiba) de Assuntos Metropolitanos (Smam), } \\
\text { Associação dos Municípios da RMC (Assomec). }\end{array}$ \\
\hline
\end{tabular}

Continua 


\begin{tabular}{|c|c|c|}
\hline RM & Ano de Criação & Tipo de Arranjo \\
\hline Fortaleza & 1973 & Conselhos Deliberativo e Consultivo \\
\hline Goiânia & 1999 & $\begin{array}{l}\text { Conselho de Desenvolvimento da Região Metropolitana de Goiânia (Codemetro), } \\
\text { de caráter normativo e deliberativo, cuja secretaria executiva é exercida pela Supe- } \\
\text { rintendência da Região Metropolitana de Goiânia, da Secretaria das Cidades. }\end{array}$ \\
\hline Maringá & 1998 & $\begin{array}{l}\text { Coordenadoria da Região Metropolitana de Maringá (Comem), Parlamento Metro- } \\
\text { politano e Associação dos Municípios do Setentrião Paranaense (Amusep). }\end{array}$ \\
\hline Natal & 1997 & $\begin{array}{l}\text { Conselho de Desenvolvimento Metropolitano de Natal (CDRMN) e Parlamento } \\
\text { Metropolitano. }\end{array}$ \\
\hline Porto Alegre & 1973 & $\begin{array}{l}\text { Fundação Estadual de Planejamento Metropolitano e Regional (Metroplan), como } \\
\text { órgão de apoio técnico do Conselho Deliberativo da RMPA. }\end{array}$ \\
\hline Recife & 1973 & $\begin{array}{l}\text { Sistema Gestor Metropolitano (SGM), que compreende o Conselho de Desenvolvi- } \\
\text { mento da Região Metropolitana do Recife (Conderm), órgão deliberativo e consultivo; } \\
\text { a Fundação de Desenvolvimento da Região Metropolitana do Recife (Fidem), uma } \\
\text { secretaria executiva de apoio técnico; e o Fundo de Desenvolvimento da Região } \\
\text { Metropolitana do Recife (Funderm). }\end{array}$ \\
\hline Rio de Janeiro & 1974 & Conselhos Consultivo e Deliberativo \\
\hline Salvador & 1973 & Companhia de Desenvolvimento Urbano do Estado da Bahia (Conder) \\
\hline São Paulo & 1973 & $\begin{array}{l}\text { Conselho Deliberativo da Grande São Paulo (Codegran), Conselho Consultivo Me- } \\
\text { tropolitano de Desenvolvimento Integrado da Grande São Paulo (Consulti), Empresa } \\
\text { Paulista de Planejamento Metropolitano AS (Emplasa), vinculada à Secretaria de } \\
\text { Economia e Planejamento do Estado de São Paulo, e Conselho de Desenvolvimento, } \\
\text { de caráter normativo e deliberativo. }\end{array}$ \\
\hline Aracaju & $1995 / 2003$ & $\begin{array}{l}\text { Conselho de Desenvolvimento da Região Metropolitana de Aracaju (Condemetro), } \\
\text { de caráter deliberativo, normativo e consultivo. }\end{array}$ \\
\hline Baixada Santista & 1996 & $\begin{array}{l}\text { Agência Metropolitana da Baixada Santista (Agem), composta por Conselhos Deli- } \\
\text { berativo e Normativo, que constituem o Conselho de Desenvolvimento da Região } \\
\text { Metropolitana. }\end{array}$ \\
\hline Campinas & 2000 & $\begin{array}{l}\text { Agência Metropolitana de Campinas (Agemcamp), composta por Conselhos Deli- } \\
\text { berativo e Normativo, que constituem o Conselho de Desenvolvimento da Região } \\
\text { Metropolitana. }\end{array}$ \\
\hline João Pessoa & 2003 & $\begin{array}{l}\text { Conselho de Desenvolvimento Metropolitano, de caráter consultivo, normativo e } \\
\text { deliberativo, que integra o Consórcio de Desenvolvimento Intermunicipal da Região } \\
\text { Metropolitana de João Pessoa (Condiam-PB) }\end{array}$ \\
\hline Londrina & 1998 & $\begin{array}{l}\text { Coordenação da Região Metropolitana de Londrina (Comel), Conselhos Deliberativo } \\
\text { e Consultivo. }\end{array}$ \\
\hline Maceió & 1998 & $\begin{array}{l}\text { Sistema Gestor Metropolitano (SGM), órgão deliberativo e consultivo, Conselho de } \\
\text { Desenvolvimento da Região Metropolitana de Maceió, Secretaria Executiva da RMM } \\
\text { e Fundo de Desenvolvimento da Região Metropolitana de Maceió (Funderm). }\end{array}$ \\
\hline Vale do Aço & 1998 & $\begin{array}{l}\text { Assembleia Metropolitana, Agência de Desenvolvimento Metropolitano, Fundo de } \\
\text { Desenvolvimento Metropolitano do Vale do Aço e Conselho Deliberativo de Desen- } \\
\text { volvimento da RMVA. }\end{array}$ \\
\hline
\end{tabular}




\begin{tabular}{|c|c|c|}
\hline RM & Ano de Criação & Tipo de Arranjo \\
\hline Grande Vitória & 1995 & $\begin{array}{l}\text { Conselho Metropolitano da Grande Vitória (CMGV), Conselho Metropolitano de } \\
\text { Desenvolvimento da Grande Vitória (Comdevit), Fundo Metropolitano de Desen- } \\
\text { volvimento da Grande Vitória (Fumdevit). }\end{array}$ \\
\hline Distrito Federal & 1998 & $\begin{array}{l}\text { Conselho Administrativo da Região Integrada de Desenvolvimento do Distrito Federal } \\
\text { e Entorno (Coaride). }\end{array}$ \\
\hline Juazeiro/Petrolina & 2001 & $\begin{array}{l}\text { Conselho Administrativo da Região Integrada de Desenvolvimento do Polo Petrolina } \\
\text { e Juazeiro (Coaride Petrolina/Juazeiro). }\end{array}$ \\
\hline Teresina/Timon & 2001 & $\begin{array}{l}\text { Conselho Administrativo da Região Integrada de Desenvolvimento da Grande Teresina } \\
\text { (Coaride Teresina). }\end{array}$ \\
\hline
\end{tabular}

Fonte: Ribeiro e Santos Junior (2010:62-64).

Os arranjos metropolitanos ainda são poucos e estão em evolução em seu desenho institucional, evolução esta que depende da dinâmica política estadual e do município núcleo, sobretudo em capitais. Deve-se destacar a importância do governo estadual na coordenação das RMs, o que permite superar os problemas de assimetria de porte intramunicipal. Além disso, na formação da aglomeração urbana, o município que possui o núcleo central de expansão urbana acaba sendo o agente indutor do processo de condução gerencial metropolitana numa perspectiva de ação centrípeta. Isso decorre do fato de as relações existentes dos núcleos periféricos estarem voltadas para o núcleo central, devido principalmente à sua importância política e econômica (Gouvêa, 2005).

A centralidade intrametropolitana no município núcleo, característica da metropolização brasileira, mostra que, apesar do crescimento dos municípios periféricos das áreas metropolitanas, as principais atividades econômicas, sobretudo emprego e serviços, permanecem no núcleo central urbano do aglomerado. Em muitos casos, nas RMs brasileiras observa-se que os municípios que integram a aglomeração urbana são considerados cidades dormitórios. Isso acompanha a natureza do processo de segregação urbana e de expansão do mercado imobiliário, ou seja, dada a valorização imobiliária do município núcleo central, os indivíduos que compõem a força de trabalho passam a residir nas áreas residenciais de melhor aquisição em termos de custo e benefício. Geralmente esses conjuntos habitacionais estão localizados nas zonas perimetrais do núcleo central e terminam por contribuir para o fenômeno da conurbação. Daí a importância da gestão metropolitana para o estabelecimento de um planejamento integrado, que possa dar conta de leis de uso de solo entre os municípios limítrofes que formam a região metropolitana. Além disso, a elevada densidade demográfica e a consequente conurbação reproduzem uma maior interação funcional diante da estrutura político-administrativa existente. Serviços públicos como transporte e limpeza urbana são fundamentais nestes municípios que, na maior parte das vezes, como foi observado no capítulo anterior, têm suas finanças rigidamente comprometidas com recursos vinculados e transferências em setores como saúde e educação.

Outro elemento a destacar é a proliferação de RMs no país desde a Constituição até aqui. Cabe ressaltar que muitas destas RMs criadas não possuem a aglomeração urbana ne- 
cessária, ou seja, as dimensões populacionais e territoriais que justificassem sua existência. Começa a se observar no Brasil que a criação de RMs segue um critério político que gira em torno da barganha dos municípios com o governo estadual. Daí a importância de um marco regulatório federal que possa ordenar e limitar a "franquia livre" pelos governos estaduais de regiões metropolitanas no Brasil, caso contrário, estar-se-á de novo diante do mesmo tipo de "Leviatã fraco" que tornou possível as emancipações municipais no início dos anos 1990. O efeito de proliferar regiões metropolitanas sem a devida preocupação com critérios definidores que as regulamentem, assim como se deu com municípios no início dos anos 1990, já é sabido: vão sendo criadas RMs sem capacidade institucional, ou seja, elas ficam apenas como letra morta de lei. E, como foi visto quando se analisaram os arranjos metropolitanos, muitas das RMs não começaram a funcionar efetivamente, ainda que elas existam legalmente.

De acordo com estudo do Observatório das Metrópoles organizado por Ribeiro (2009), dentro das 43 RMs e Rides existentes, apenas 15 espaços urbanos podem ser considerados efetivamente metropolitanos; são eles: São Paulo, Rio de Janeiro, Belo Horizonte, Porto Alegre, Brasília, Curitiba, Salvador, Recife, Fortaleza, Campinas, Manaus, Vitória, Goiânia, Belém e Florianópolis. O estudo justifica este argumento a partir do diagnóstico de que muitas regiões que surgiram possuem unidades regionais muito diferenciadas, bem como não obedecem a critérios claros, objetivos e consistentes, tanto da institucionalização como da identificação dos municípios. E os 15 espaços urbanos metropolitanos, além de obedecerem aos critérios da pesquisa (integração, concentração e condição social), representam expressiva concentração das forças produtivas do país (Ribeiro, 2009).

\section{Considerações finais}

O trabalho buscou mostrar que a trajetória de evolução da gestão metropolitana no Brasil ainda se encontra aberta no que se refere ao seu processo "político no tempo". Tentou-se demonstrar que o municipalismo autárquico da Constituição de 1988 não foi capaz de inibir a gestão metropolitana, mas, pelo contrário, ele foi o elemento que faz ressurgir a discussão acerca da esfera metropolitana como elemento importante na política urbana no Brasil.

Como foi indicado na seção 2 , acerca do referencial teórico relacionado à problemática das regiões metropolitanas, esta mostra uma conjuntura causal de curto prazo e o horizonte de tempo na observação de algum resultado de longo prazo. Dado que ainda não se observam resultados concretos, estes se encontram em aberto. A trilha da gestão metropolitana desde a Constituição de 1988 até aqui foi longa e cheia de obstáculos e ainda existe um vasto caminho a seguir. É um processo ainda em construção que requer esforço e tem alguns elementos críticos característicos que foram tratados no texto. $\mathrm{O}$ primeiro deles diz respeito à ausência de um marco legal. O Estatuto da Metrópole que tramita no Congresso desde 2004 deve seguir em frente e ser aprovado, pois, tal como o Estatuto da Cidade, criado em 2001, virá a estabelecer para as Regiões Metropolitanas regras e mecanismos de funcionamento e financiamento, capazes de auxiliar na organização metropolitana. Além disso, outros atores 
como Ministério Público, Poder Judiciário e Tribunais de Contas serão capazes, com regras claras, de exercer pressão e fiscalização institucional, a chamada "accountability horizontal", em face do governo estadual e da autoridade metropolitana.

Um segundo elemento diz respeito ao engajamento dos governos estaduais na organização da região metropolitana, que se tornará mais intenso, à medida que uma legislação como o Estatuto das Metrópoles exista. Entretanto, os governos estaduais, na maior parte das vezes, não estão dispostos a dispensar recursos para as regiões metropolitanas, ou tampouco ajudar a constituir fundos específicos. Cabe ressaltar, sem o apoio dos governos estaduais torna-se cada vez mais difícil uma política de agregação intermunicipal metropolitana que possua autoridade metropolitana com governabilidade e legitimidade de poder.

Um terceiro elemento diz respeito às formas de cooperação intramunicipal, e aí os municípios núcleos das regiões metropolitanas têm um importante papel. Evidentemente, como foi visto, sempre existirão problemas de ação coletiva, pois o município núcleo, normalmente capital de estado, que possui bom provimento de infraestrutura e serviços, não está disposto a "pagar" mais em relação aos menores na organização metropolitana. E foi visto também ao longo do texto que a maioria dos municípios metropolitanos é pequena e média, ou seja, sofre profunda influência do município grande núcleo que na maior parte das vezes é a capital do estado.

Um quarto elemento importante a se notar são os primeiros efeitos que surgem da agregação metropolitana pós-Constituição de 1988, em que se observa que começa a haver uma proliferação de regiões metropolitanas no país. Como foi visto, certas regiões metropolitanas foram criadas sem a dimensão populacional ou econômica regional que as justificasse. E em algumas dessas regiões metropolitanas existem fortes indícios de troca política entre governador e prefeitos, tal como ocorreu nos anos 1990 com as emancipações municipais. Mais uma vez, a ausência de um marco legal que estabeleça os limites de criação de regiões metropolitanas deixa os governos estaduais com exclusivo poder nisso.

Por fim, acredita-se aqui que o assunto gestão metropolitana no Brasil permanece ainda bastante inconcluso, seja qual for sua perspectiva de análise. Isso se deve tanto à complexidade do fenômeno, quanto ao modo brasileiro de tratá-lo politicamente. Enfim, é um momento aberto a inovações e mudanças nas regiões metropolitanas, mudanças estas que apresentarão novos caminhos para a gestão metropolitana no Brasil.

\section{Referências}

ABRUCIO, Fernando L. A coordenação federativa no Brasil: a experiência do período FHC e os desafios do governo Lula. Revista de Sociologia Política, Curitiba, v. 24, p. 41-67, jun. 2005.

AFONSO, Rui de B. A. Descentralização e Reforma do Estado: a federação brasileira na encruzilhada. Economia e Sociedade, Campinas, n. 14, p. 127-152, 2000.

ALMEIDA, Maria H. T. Recentralizando a federação? Revista de Sociologia Política, Curitiba, v. 24, p. 29-40, jun. 2005. 
ARRETCHE, Marta. Estado federativo e políticas sociais: determinantes da descentralização. São Paulo: Revan; Fapesp, 2000.

BERGER, Suzanne (Ed.). Organizing interests in Western Europe. Cambridge: Cambridge University Press, 1981.

BREMAEKER, François. As receitas tributárias municipais em 2009. Estudo Técnico no 113. Fórum Permanente de Secretários de Finanças do Estado da Bahia. Set. 2010.

CALDAS, Eduardo L. Criação de municípios no estado de São Paulo entre 1991 e 1996: uma abordagem institucionalista. Dissertação (mestrado) - Escola de Administração de Empresas de São Paulo, Fundação Getulio Vargas, São Paulo, 2002.

COLLIER, David; COLLIER, Ruth. Shaping The political arena. Critical junctures, the labor movement, and regime dynamics in Latin America. Princeton: Princeton University Press, 1991.

CONFEDERACÃO NACIONAL DOS MUNICÍPIOS. A situação financeira dos municípios brasileiros: avaliação das despesas e receitas próprias de 2000 a 2007. 2009. Disponível em: <www.cnm.org.br/ index.php?option $=$ com_docmanetask $=$ cat_viewegid $=104$ eltemid $=4>$. Acesso em: 2 nov. 2011.

COX, Robert. The path dependency of an idea: why Scandinavian welfare states remain distinct. Social Policy and Administrative, v. 38, n. 2, p. 204-219, 2004.

FARIA, Carlos A. Gestão metropolitana e relações governamentais assimétricas. O caso dos pequenos municípios da região metropolitana de Belo Horizonte. In: CONGRESSO INTERNACIONAL DEL CLAD, XIII, 2008, Buenos Aires. Anais eletrônicos.

FERNANDES, Antonio S. A. Gestão municipal versus gestão metropolitana: o caso da cidade de Salvador. Cadernos Metrópole, São Paulo, n. 11, p. 41-72, 2004.

FERNANDES, Edésio. O elo perdido: o desafio da gestão metropolitana. In: ALFONSIN, Betaniade M.; FERNANDES, Edésio (Org). Direito urbanístico, estudos brasileiros e internacionais. Belo Horizonte: Del Rey, 2006. p. 359-390.

GARSON, Sol. Regiões metropolitanas: por que não cooperam? Rio de Janeiro: Letra Capital: Observatório das Metrópoles; Belo Horizonte: PUC-MG, 2009.

GOUVÊA, Ronaldo G. A questão metropolitana no Brasil. Rio de Janeiro: Editora FGV, 2005.

GREENER, Ian. The Potential of path dependence in political studies. Politics, v. 25, n. 1, p. 62-72, 2005 .

KATO, Junko. Path dependency as a logic of comparative studies: theorization and application. In: ANNUAL MEETING OF AMERICAN POLITICAL SCIENCE ASSOCIATION (APSA), 1996, San Francisco. Manuscrito.

MACHADO, Gustavo G.; SOUKI, Lea G.; FARIA, Carlos A. P. Processo legislativo, articulação intergovernamental e gestão metropolitana: inovação institucional e participação social na Região Metropolitana de Belo Horizonte. In: CONGRESSO BRASILEIRO DE SOCIOLOGIA, GT 02: Cidades e processos sociais, XIII, 2007, Recife. Resumos. Recife: SBS, 2007. v. 1, p. 67. 
MAGNUSSON, Lars; OTTOSSON, Jan. The evolution of path dependence. Chaltenham, UK: Edward Elgar Publishing Limited, 2009.

MAHONEY, James; SCHENSUL, Daniel. Historical context and path dependence. In: BOX, Carles; STOKES, Susan C. The Oxford handbook of comparative politics. Nova York: Oxford University Press Inc., 2007.

MELO, Marcus. Federalismo e política social: as vicissitudes da descentralização. In: MELO, Norma L.; LEAL, Suely M. R. (Org.). Relação público-privado: do local ao global. Recife: Edufpe, 1996.

MENDES, Marcos et al. Transferências intergovernamentais no Brasil: diagnóstico e proposta de reforma. Consultoria Legislativa do Senado Federal. Coordenação de estudos. Textos 40. Brasília, abr. 2008.

OLIVEIRA, Fabricio. A evolução da estrutura tributária e do fisco brasileiro: 1889-2009. Texto para discussão 1469. Brasília: Ipea, jan. 2010.

OLSON, Mancur. The principle of "fiscal equivalence": the division of responsibilities among different levels of government. The American Economic Review, v. 59, n. 2, p. 479-487, 1969.

PENALVA SANTOS, Angela M. Descentralização, desenvolvimento local e autonomia financeira dos municípios. Quivera, México, v. 10, n. 1, p. 47-64, enero/jun. 2008.

PIERSON, Paul. Big, slow-moving, and...invisible: macrosocial process in the study of comparative politics. In: MAHONEY, James; RUESCHMEYER, Dietrich (Ed.). Comparative historical analysis in social sciences. Nova York: Cambridge University Press, 2003. p. 177-207.

PIERSON, Paul. Increasing returns, path dependency, and study of politics. American Political Science Review, v. 94, n. 2, p. 251-267, June 2000.

PIERSON, Paul. Politics in time. Princeton: Princeton University Press, 2004.

PUTNAM, Robert. Comunidade e democracia. A experiência da Itália moderna. Rio de Janeiro: Fundação Getulio Vargas, 1996. [Tradução de Making democracy work]

REZENDE, Fernando. Federalismo fiscal no Brasil. Revista de Economia Política, v. 15, n. 3, p. 5-17, jul./set. 1995.

REZENDE, Flavio. Da exogeneidade ao gradualismo: inovações na teoria da mudança institucional. Revista Brasileira de Ciências Sociais, v. 27, n. 78, p. 113-130, fev. 2012.

RIBEIRO, Luiz C. de Q. A Metrópole: entre a coesão e a fragmentação, a cooperação e o conflito. In: RIBEIRO, Luiz C. de Q.; LAGO, Luciana Correa; AZEVEDO, Sérgio (Org.). Metrópoles: entre a coesão e a fragmentação, a cooperação e o conflito. São Paulo: Fundação Perseu Abramo; Rio de Janeiro: Fase, 2004. v. 1, p. 17-40.

RIBEIRO, Luiz C. de Q. (Org.). Hierarquização e identificação dos espaços urbanos. Rio de Janeiro: Letra Capital: Observatório das Metrópoles, 2009. (Conjuntura urbana; 1)

RIBEIRO, Luiz C. de Q.; SANTOS JUNIOR, Orlando A. As grandes cidades e a questão social brasileira: reflexões sobre o Estado de exceção nas metrópoles brasileiras. In: CASTRO, Erika de; WOJCIE- 
CHOWSKI, Maciej John (Org.). Inclusão, colaboração e governança urbana: perspectivas brasileiras. Vancouver: The University of Bristish Columbia; Rio de Janeiro: Observatório das Metrópoles; Belo Horizonte: Ed. PUC-MG, 2010. p. 62-64.

SOUZA, Celina. Federalism and regional interest intermediation in Brazilian public policies. Public Administration and Development, v. 19, p. 263-279, 1999.

SOUZA, Celina. Regiões metropolitanas: condicionantes do regime político. Lua Nova - Revista de Cultura e Política, São Paulo, n. 59, p. 137-158, 2003.

SPINK, Peter K.; TEIXEIRA, Marco A. C.; CLEMENTE, Roberta. Governança, governo ou gestão: o caminho das ações metropolitanas. Cadernos Metrópole, São Paulo, v. 11, n. 22, p. 453-476, jul./ dez. 2009.

THELEN, Kathleen. How institutions evolve: insights from comparative historical anaysis. In: MAHONEY, James; RUESCHMEYER, Dietrich (Ed.). Comparative historical analysis in social sciences. Nova York: Cambridge University Press, 2003. p. 208-240.

Antônio Sérgio Araújo Fernandes é professor adjunto e pesquisador do Programa de Pós-Graduação em Administração da Universidade Federal do Rio Grande do Norte (PPGA//UFRN). E-mail: antoniosergio07@gmail.com.

Robert H. Wilson é LBJ School — Associate Dean for Academic Affairs and Research, Mike Hogg Professor in Urban Policy. E-mail: rwilson@austin.utexas.edu. 